\title{
Determinants of sexual intercourse initiation among incarcerated adolescents: a mixed-method study
}

\author{
Nik Daliana Nik Farid ${ }^{1,2,3}$, MPH, DrPH, Sulaiman $\underline{\text { Che' Rus }}^{4}$, MBBs, MPH, Maznah Dahlui ${ }^{1}$, MPH, PhD, \\ Nabilla Al-Sadat ${ }^{1,2}$, MPH, PhD
}

INTRODUCTION This study aimed to investigate the determinants of sexual intercourse initiation among incarcerated adolescents aged 12-19 years in Malaysia.

METHODS This was a sequential mixed-method research project that was conducted in two phases. Quantitative and qualitative methods were used in the first and second phases, respectively. Data was collected via a survey using self-reported questionnaires from 1,082 adolescents, and from in-depth interviews and the written essays of 29 participants. The participants were recruited from 22 welfare institutions in peninsular Malaysia.

RESULTS Among the study participants, 483 were male and 599 were female. Overall, $62.3 \%$ of the incarcerated adolescents had initiated sexual intercourse at least once. The mean age at first sexual intercourse for both genders was 14.0 years. Individual factors found to be associated with previous sexual intercourse were the female gender (odds ratio [OR] 1.75; 95\% confidence interval [CI] 1.11-2.74), previous alcohol use (OR 1.80; 95\% Cl 1.10-2.94), previous illicit drug use $(\mathrm{OR} 1.85 ; 95 \% \mathrm{Cl} 1.07-3.22)$, permissive attitude toward premarital sex $(\mathrm{OR} 4.34 ; 95 \% \mathrm{Cl}$ 2.17-8.70), and sexual abuse during childhood (OR 5.41; 95\% $\mathrm{Cl} 3.52-8.32$ ). Qualitative findings revealed that the reasons for initiation of sexual intercourse among these adolescents were partner influence, inability to control sex drive, family issues, and the perception of sex as an expression of love.

CONCLUSION The determinants of sexual intercourse initiation among incarcerated Malaysian adolescents are comparable to those of developed countries. However, in Malaysia, sexual and reproductive health programmes for such adolescents should be tailored to address their specific needs.

Keywords: incarcerated adolescents, sexual intercourse initiation, welfare institutions

\section{INTRODUCTION}

Adolescence is characterised by dramatic changes in the physical, psychological, social and spiritual spheres of life.(1) In 2011, the United Nations Children's Fund reported that the worldwide population of individuals between 10 and 19 years of age was 1.2 billion.(2) Of these 1.2 billion, approximately 660 million adolescents are from the Asia Pacific Region, which includes Malaysia. ${ }^{(2)}$ Adolescents represent $19.2 \%$ of the total population in Malaysia. ${ }^{(3)}$

In general, adolescents are at a higher risk of contracting HIV/AIDS and sexually transmitted infections (STIs). ${ }^{(4,5)}$ Studies conducted in different parts of the world have shown that adolescents who engage in sexual activity early are at higher risk of its consequences. One study in the United States found that an 18-year-old whose first intercourse occurred the age of 13 years was more than twice as likely to have an STI than an 18-year-old whose first intercourse occurred the age of 17 years (odds ratio [OR] 2.25; 95\% confidence interval [CI] 1.42-3.59). ${ }^{(6)}$ Similarly, in China, men who initiated sex at an early age were found to be at a higher risk of contracting STIs than late initiators (OR 26.13; 95\% Cl 2.94-232.09). ${ }^{(7)}$ The deleterious effects of having sex at an early age have also been well documented among incarcerated adolescents, e.g. juvenile offenders. ${ }^{(8-11)}$ Sexual activities among these adolescents have been associated with alcohol use, illicit drug use and child sexual abuse.

Although incarcerated adolescents are among the most vulnerable individuals in Malaysia, their sexual and reproductive health is rarely seen as a priority. An understanding of the factors influencing the initiation of intercourse may present opportunities to create new programmes designed to delay intercourse or discourage premarital sex in this group of adolescents. Additionally, such an understanding may encourage new ways of conceptualising the management of adolescents who have already initiated sexual intercourse within welfare institutions. Hence, the main objective of this study was to conduct an in-depth examination of the determinants of sexual initiation in a sample of adolescents within the Malaysian institutional system.

\section{METHODS}

The study utilised both quantitative and qualitative methods of data collection, which was conducted in two phases from October 2009 to September 2010. In the quantitative phase, the study population constituted 1,082 adolescents from 22 welfare institutions in 11 states of peninsular Malaysia. Welfare institutions were defined as facilities in which adolescents received shelter and rehabilitation following contact with the

\footnotetext{
${ }^{1}$ Department of Social and Preventive Medicine, ${ }^{2}$ Centre for Population Health (CePH), Faculty of Medicine, University of Malaya, Kuala Lumpur, ${ }^{3}$ Ministry of Health Malaysia, ${ }^{4}$ Institute for Health Behavioural Research, Ministry of Health Malaysia, Putrajaya, Malaysia

Correspondence: Dr Nik Daliana Nik Farid, Medical Lecturer, Department of Social and Preventive Medicine, Faculty of Medicine, University of Malaya, 50603 Kuala Lumpur, Malaysia. daliana@ummc.edu.my
} 
judicial system for cases of neglect, child abuse or breaking of the law. ${ }^{(12)}$ Using the OpenEpi Software, ${ }^{(13)}$ the sample size was calculated on the basis of findings on the prevalence of sexual initiation from the National Health and Morbidity Survey 2006. ${ }^{(14)}$ Based on the formula for sample size calculation, the minimum required sample size was 768 . A total of 1,082 participants were recruited, thus exceeding the minimum requirement for this study.

The inclusion criteria were boys or girls aged 12-19 years who were not married at the time of the study, and able to understand and communicate in either written or spoken Malay or English. The aim of the quantitative phase was to determine the prevalence of sexual initiation and its associated factors. Data was collected using a self-administered questionnaire. Pre-testing and test-retest of the Malay translated version was undertaken, and it was found to be compatible with Malaysian adolescents. Quantitative data was entered into the Predictive Analytics Software version 17, (SPSS Inc, Chicago, IL, USA) to elicit the appropriate descriptive, univariate and multiple logistic regression analyses. Associating factors of sexual initiation were determined using binary logistic regression (backward logistic regression method), of which nine variables were included in the initial model.

The main topics covered in the questionnaire and the independent measures are discussed below:

(a) Sociodemographic information - information on gender, age, ethnicity, religion and educational status was collected from the participants.

(b) Parental monitoring - the Parental Monitoring Assessment, which consisted of a 5-point Likert scale ranging from 1 to 5 $(1=$ 'never' and $5=$ 'always' $)$ assesses an adolescent's perception of their parents' supervision, and respondents were classified as having low or high parental monitoring perception. ${ }^{(15,16)}$ This scale was found to be reliable, with a Cronbach's $\alpha$ value of 0.84 following evaluation. Permission to use this scale was granted by Professor Steven Small from the University of Wisconsin.

(c) Self-esteem - the Rosenberg Self-Esteem scale measures the adolescents' levels of self-esteem. This scale was previously validated in Malaysian adolescents ${ }^{(17)}$ who were asked to respond to ten items on self-esteem, and the subscales were scored according to standard scoring methods. ${ }^{(18-20)}$ Participants' self-esteem levels were determined using standard scoring methods. In the current study, the scale was reliable with a correlation coefficient of 0.69 .

(d) History of substance use - the participants were evaluated for their history of substance use (e.g. alcohol, cigarettes and illicit drugs) with the aid of questions such as "Have you ever smoked a cigarette (at least one or two puffs) or tried any tobacco products such as cigars or shisha?" $(\kappa=1)$; "Have you smoked in the past one month?" $(\kappa=1)$; "Have you ever consumed alcohol?" ( $\kappa=1)$; and "Have you ever used illicit drugs?" $(\kappa=1)$. Those who answered 'Yes' to any of the
Table I. Sociodemographic characteristics of the study participants $(n=1,082)$.

\begin{tabular}{lc}
\hline Variable & No. (\%) \\
\hline Gender & \\
Male & $483(44.6)$ \\
Female & $599(55.4)$ \\
Age group (yrs) & \\
$12-14$ & $258(23.8)$ \\
$15-17$ & $699(64.6)$ \\
$18-19$ & $125(11.6)$ \\
Ethnicity* & \\
Malay & $939(86.9)$ \\
Chinese & $38(3.5)$ \\
Indian & $92(8.5)$ \\
Others & $12(1.1)$ \\
Religion* & \\
Islam & $974(90.1)$ \\
Buddhism & $23(2.1)$ \\
Christianity & $17(1.6)$ \\
Hinduism & $59(5.5)$ \\
Others & $4(0.4)$ \\
No religion & $4(0.4)$ \\
Educational status ${ }^{+}$ & \\
Primary & \\
Secondary & $154(14.6)$ \\
Tertiary & $875(82.7)$ \\
No education & $10(0.9)$ \\
\hline
\end{tabular}

${ }^{*}$ Data is missing for 1 case. ${ }^{\dagger}$ Data is missing for 24 cases.

Note: ${ }^{*, \dagger}$ Percentages are calculated based on less than 1,082 participants due to missing data.

aforementioned questions were categorised as either smokers, alcohol drinkers or previous illicit drug users.

(e) Knowledge of sexual health - this was assessed using six questions adapted from the National Health and Morbidity Survey III ${ }^{(14)}$ and Teenage Knowledge of Contraception and Sexual Health: Questionnaire Study in West Yorkshire.(21) The six questions included "Can a person become pregnant after one act of sexual intercourse?"; "Have you heard of contraception?"; "What are the different types of contraception available?"; "Do you know about STIs?"; "What are the different types of STIs?"; and "From the list below, can you identify the symptoms of STIs?" Based on the total score, the participants were categorised as either having adequate or inadequate knowledge of sexual health. In the present study, a moderate agreement $\kappa$ value of 0.41 was generated.

(f) Child abuse - this was assessed on the basis of the participants' responses to questions on child sexual and physical abuse. Questions for this variable were adapted from the Sexual and Physical Abuse Questionnaire by Kooiman et al. ${ }^{(22)}$ The adapted items included the following questions: "Has anyone ever touched your sex organs in a sexual manner and against your will?"; "Has anyone ever forced you to touch his or her sex organs in a sexual manner and against your will?"; "Has anyone ever forced you to have sexual intercourse against your will?"(22); and "Have you ever intentionally been treated by someone in such a way that you suffered physical injury (e.g. beaten, stamped on, kicked or pushed)?"(22) Participants who 
Table II. Relationship between individual components and previous sexual intercourse.

\begin{tabular}{|c|c|c|c|c|}
\hline \multirow[t]{2}{*}{ Individual component ${ }^{+}$} & \multicolumn{2}{|c|}{ Previously engaged in sexual intercourse* } & \multirow{2}{*}{$\begin{array}{l}\text { Odds } \\
\text { ratio }\end{array}$} & \multirow{2}{*}{$\begin{array}{c}95 \% \text { confidence } \\
\text { interval }\end{array}$} \\
\hline & Yes & No & & \\
\hline \multicolumn{5}{|l|}{ Educational level } \\
\hline Primary & $58(9.0)$ & $88(22.9)$ & 1.32 & $0.47-3.7$ \\
\hline Secondary & $575(89.1)$ & $283(73.5)$ & 4.06 & $1.51-10.9$ \\
\hline Tertiary & $6(0.9)$ & $2(0.5)$ & 6.00 & $0.92-39.2$ \\
\hline No education & $6(0.9)$ & $12(3.1)$ & 1.00 & \\
\hline \multicolumn{5}{|l|}{ Self-esteem } \\
\hline Low & $299(49.5)$ & $110(35.9)$ & 1.75 & $1.32-2.32$ \\
\hline High & $305(50.5)$ & $196(64.1)$ & & \\
\hline \multicolumn{5}{|l|}{ Ever smoked } \\
\hline Yes & $532(81.6)$ & $236(60.1)$ & 2.95 & $2.22-3.91$ \\
\hline No & $120(18.4)$ & $157(39.9)$ & & \\
\hline \multicolumn{5}{|l|}{ Ever consumed alcohol } \\
\hline Yes & $351(53.8)$ & $79(20.2)$ & 4.62 & $3.45-6.18$ \\
\hline No & $301(46.2)$ & $313(79.8)$ & & \\
\hline \multicolumn{5}{|l|}{ Previous illicit drug use } \\
\hline Yes & $283(43.3)$ & $54(13.7)$ & 4.80 & $3.47-6.65$ \\
\hline No & $370(56.7)$ & $339(86.3)$ & & \\
\hline \multicolumn{5}{|c|}{ Attitude regarding premarital sex } \\
\hline Favourable & $175(29.0)$ & $22(7.3)$ & 5.19 & $3.25-8.29$ \\
\hline Unfavourable & $429(71.0)$ & $280(92.7)$ & & \\
\hline \multicolumn{5}{|c|}{ Knowledge of sexual and reproductive health } \\
\hline Inadequate & $412(63.8)$ & 294 (79.9) & 0.44 & $0.33-0.60$ \\
\hline Adequate & $234(36.2)$ & $74(20.1)$ & & \\
\hline \multicolumn{5}{|c|}{ History of sexual abuse during childhood } \\
\hline Yes & $445(68.1)$ & $94(24.0)$ & 6.78 & $5.10-9.01$ \\
\hline No & 208 (31.9) & $298(76.0)$ & & \\
\hline \multicolumn{5}{|l|}{ Pornography viewing } \\
\hline Yes & $602(92.0)$ & $246(62.8)$ & 6.87 & $4.84-9.75$ \\
\hline No & $52(8.0)$ & $146(37.2)$ & & \\
\hline
\end{tabular}

${ }^{*}$ Data is presented as no. (\%); all percentages are calculated based on less than 1,082 participants due to missing data.

${ }^{\dagger}$ The sample size included in the bivariate analysis for each variable is smaller than the total sample of 1,082 due to missing data.

responded 'Yes' to any of the questions were categorised as having had a history of child sexual or physical abuse. ${ }^{(23)}$

The qualitative phase was specifically designed to obtain a deeper understanding of the factors that contribute to sexual initiation among male and female adolescents. A total of 29 adolescents who admitted to having had previous sexual intercourse were included through purposeful sampling. In-depth interviews and essay writing exercises were conducted. The participants' perceptions in relation to their sexual initiation were obtained through probing questions such as "Tell me about the first time you had sex" and "Why did you first have sex when you did?" Subjects who were uncomfortable discussing sexual behaviour verbally or opted to not be interviewed at all were given the option of writing essays. The interview sessions were recorded and written essays were copied onto Microsoft Word (Microsoft Inc, Redmond, USA). Data was then entered into Nvivo 8 software (QSR International, Doncaster, VIC, Australia) for data management and interpretation of results.

Ethical clearance for the study was obtained from the ethics committee of the University of Malaya Medical Centre. Informed consent was obtained from the adolescents' current guardians, i.e. the Social Welfare Department of Malaysia. Additionally, verbal consent was sought from the study participants before the start of the interview and essay writing exercise. The participants were provided detailed information concerning the purpose and nature of the research before their consent was obtained.

\section{RESULTS}

Of the 1,082 participants, $483(44.6 \%)$ were male and $599(55.4 \%)$ were female. The mean age of the participants was 15.7 (range 12-19) years. The predominant ethnicity in our study was Malay, which comprised $86.9 \%$ of the participants. Table I shows the distribution of the sociodemographic characteristics of the adolescents in the study.

A total of 1,049 adolescents completed the item on past sexual activity. Among these adolescents, 654 (62.3\%) had initiated sexual intercourse at least once. The mean age at first sexual intercourse was 14.0 (range 8-19) years. A significantly higher percentage of females $(68.1 \%)$ experienced sexual intercourse as compared to males (55.0\%). Factors significantly associated with having experienced sexual intercourse were a history of sexual abuse during childhood, attitudes toward premarital sex, previous alcohol and illicit drug use, and viewing of pornography (Table II).

Logistic regression conducted to determine the predictors of previous engagement in sexual intercourse showed that the strongest predictors were a history of sexual abuse during 
Table III. Results of the multivariate logistic regression analyses peformed to determine predictors of previous engagement in sexual intercourse.

\begin{tabular}{|c|c|c|}
\hline \multirow[t]{2}{*}{ Variable } & \multicolumn{2}{|c|}{ Multivariate modelling } \\
\hline & Odds ratio & $95 \% \mathrm{Cl}$ \\
\hline \multicolumn{3}{|l|}{ Gender } \\
\hline Female & 1.75 & \multirow{2}{*}{$\begin{array}{l}1.11-2.74 \\
\text { (ref) }\end{array}$} \\
\hline Male & 1.00 & \\
\hline \multicolumn{3}{|c|}{ Previous alcohol consumption } \\
\hline Yes & 1.80 & \multirow{2}{*}{$\begin{array}{l}1.10-2.94 \\
\quad \text { (ref) }\end{array}$} \\
\hline No & 1.00 & \\
\hline \multicolumn{3}{|c|}{ Previous illicit drug use } \\
\hline Yes & 1.85 & \multirow{2}{*}{$\begin{array}{l}1.07-3.22 \\
\quad \text { (ref) }\end{array}$} \\
\hline No & 1.00 & \\
\hline \multicolumn{3}{|c|}{ Attitude regarding premarital sex } \\
\hline Permissive & 4.34 & \multirow{2}{*}{$\begin{array}{l}2.17-8.70 \\
\text { (ref) }\end{array}$} \\
\hline Not permissive & 1.00 & \\
\hline \multicolumn{3}{|c|}{$\begin{array}{l}\text { History of sexual abuse } \\
\text { during childhood }\end{array}$} \\
\hline Yes & 5.41 & \multirow{2}{*}{$\begin{array}{l}3.52-8.32 \\
\quad(\text { ref })\end{array}$} \\
\hline No & 1.00 & \\
\hline \multicolumn{3}{|c|}{ Previous pornography viewing } \\
\hline Yes & 2.84 & \multirow{2}{*}{$\begin{array}{l}1.65-4.89 \\
\text { (ref) }\end{array}$} \\
\hline No & 1.00 & \\
\hline
\end{tabular}

Note: The sample size included in logistic regression is smaller than the total sample of 1,082 due to missing data for some variables. Other variables entered include age, race, highest educational level, self-esteem, smoking, parental monitoring, parental trust, peer pressure, geographical origin, sexual and reproductive health knowledge, previous employment, family structure, religion and religiosity. Hosmer-Lemeshow chi-square goodness of fit test $=8.99$ (degrees of freedom $=8), p=0.34$, and significant area under curve $=0.851(\mathrm{p}<0.001, \mathrm{Cl}=0.83-0.88)$.

$\mathrm{Cl}$ : confidence interval

childhood (95\% Cl 3.52-8.32), followed by a permissive attitude regarding premarital sex $(95 \% \mathrm{Cl} 2.17-8.70)$, and previous viewing of pornography (95\% Cl 1.65-4.89) (Table III). Other predictors included previous use of substances such as illicit drugs and alcohol, and the female gender.

Among the 29 adolescents who participated in the qualitative component of the study, more than $50 \%$ were males. The median age of the participants was 16 (range 14-19) years, and the median age of sexual initiation was 14 (range 10-17) years. The following five main themes emerged when exploring the participants' perceptions concerning initiation of sex: (a) the use of sex as an expression of love $(n=9)$; (b) influence of the partner ( $\mathrm{n}=9$ ); (c) inability to control sex drive $(n=7)$; $(d)$ family issues $(n=7)$; and (e) history of sexual abuse during childhood $(n=5)$. Table IV shows some of the participants' responses obtained for each theme.

The qualitative findings provided insights into the quantitative results. Factors such as deeming sex as an expression of love and the inability to control sex drive supplemented the individual domain of the quantitative results, while partner influence and family issues contributed to the interpersonal domain. The theme of sexual abuse during childhood increased the validity of the quantitative results.

\section{DISCUSSION}

Sexual abuse during childhood was found to be a strong determinant of sexual initiation among the incarcerated adolescents who participated in this study. This finding was further explained by the results of the qualitative study. Adolescents who had been victims of child abuse responded that they initiated sex because of feelings of powerlessness, guilt, shame, stigmatisation and low self-esteem due to the loss of their virginity. ${ }^{(24)}$ This factor has also been associated with other consequences such as lower assertiveness and higher rates of depression. ${ }^{(24)}$ Additionally, these acts of abuse against adolescents violate their bodies and minds, obliterating boundaries and creating a deep sense of worthlessness. Consequently, these adolescents become more vulnerable and prone to engaging in inappropriate sexual intercourse. ${ }^{(24)}$ The findings of the present study support those of a previous study, which also showed that high-risk adolescents who were victims of sexual abuse were more likely to initiate sex than those who had never been sexually abused.(25)

Our findings also suggest that a permissive attitude toward premarital sex is a risk factor for engaging in sexual intercourse. Other researchers have found that adolescents' attitudes toward sex greatly influence their sexual behaviour. ${ }^{(26-28)}$ This observation is further explained by the problem behaviour theory, i.e. the attitudinal tolerance of deviance, which refers to an individual's disposition toward behaviour that goes against societal norms. ${ }^{(1)}$ This open attitude may also be due to other influences such as peers, the media and demographic factors. ${ }^{(1)}$

Consistent with the results of other studies, there was an association between sexual initiation and the viewing of pornographic material. Previous findings have consistently demonstrated that exposure to sexually explicit content, which causes desensitisation of one's attitudes and values, leads to adolescents' sexually permissive attitudes. ${ }^{(29-32)}$ Pornography viewing causes adolescents to become stimulated and induces a sexual fantasy about a partner with whom they want to have sex, which in turn influences them to initiate sex when given the opportunity.

Our study also found that previous use of alcohol and illicit drugs was associated with initiation of sexual intercourse among our study participants. Again, this result is in line with the findings of many previous studies. ${ }^{(29,33-39)}$ Alcohol is an intoxicating drug that depresses the central nervous system, impairs functional brain activity and changes thought processes and feelings. ${ }^{(40)}$ Adolescents may be more vulnerable to the effects of alcohol because they have not developed a physical tolerance for alcohol and lack experience in alcohol consumption. Similarly, the use of drugs can cause deficits in specific reasoning processes, inhibitions and physical coordination. Thus, both substances may motivate adolescents to initiate sex.

Unexpectedly, the current survey showed that female incarcerated adolescents were more likely to have engaged in sex as compared to males. One study in the Philippines has found that girls progress faster than boys through the sequence of emotional relationships associated with initiating 
Table IV. Responses of some of the participants according to the five main themes.

\begin{tabular}{|c|c|}
\hline Theme & Response \\
\hline \multirow[t]{2}{*}{$\begin{array}{l}\text { Sex as an expression of love and } \\
\text { a means of strengthening relationship }\end{array}$} & $\begin{array}{l}\text { Respondent A (male, } 16 \text { years old): "I don't want her to be close to anybody else. I want to be a } \\
\text { responsible partner to her." }\end{array}$ \\
\hline & Respondent B (female, 17 years old): "When I got together with this guy, I was so in love with him." \\
\hline \multirow[t]{2}{*}{$\begin{array}{l}\text { Partnership as a prime factor for } \\
\text { having sex }\end{array}$} & $\begin{array}{l}\text { Respondent C (female, } 18 \text { years old): "He made me feel comfortable with him. He made me not } \\
\text { feel afraid of him, and he somehow reassured me, and I felt calm around him." }\end{array}$ \\
\hline & $\begin{array}{l}\text { Respondent D (female, } 15 \text { years old): "He forced me even though I did not want it. If I did not give } \\
\text { in, he would just sulk. So I went ahead with it without thinking about it." }\end{array}$ \\
\hline \multirow[t]{2}{*}{ Inability to control sex drive* } & $\begin{array}{l}\text { Respondent E (female, } 18 \text { years old): "I constantly engaged in phone sex, and I became addicted } \\
\text { to it. At first, I just wanted to continue in the same way. However, when I met him, I wanted } \\
\text { something more." }\end{array}$ \\
\hline & $\begin{array}{l}\text { Respondent F (male, } 18 \text { years old): "I am not normal. When I am outdoors, I'm always turned on } \\
24 \text { hours a day." }\end{array}$ \\
\hline \multirow[t]{2}{*}{ Family issues } & $\begin{array}{l}\text { Respondent G (female, } 14 \text { years old): "I was fed up with my family. I was always being scolded. } \\
\text { They (my parents) took care of my other siblings but did not care about me." }\end{array}$ \\
\hline & $\begin{array}{l}\text { Respondent H (female, } 18 \text { years old): "He (father) didn't care about me, so I didn't give a damn } \\
\text { about it. That's why I was brave enough to do it (sex)." }\end{array}$ \\
\hline \multirow[t]{2}{*}{$\begin{array}{l}\text { History of sexual abuse during } \\
\text { childhood }\end{array}$} & $\begin{array}{l}\text { Respondent I (female, } 17 \text { years old): "Since I have already lost my virginity, I felt like there was } \\
\text { nothing to stop me from doing anything." }\end{array}$ \\
\hline & Respondent $\mathrm{J}$ (female, 15 years old): "I was raped by that man. I felt traumatised and stressed." \\
\hline
\end{tabular}

* Sexual urge is a biological need of adolescents, which some found difficult to control, especially when influenced by factors such as phone sex, caressing and pornographic materials.

sex. ${ }^{(41)}$ For male adolescents, the reasons for initiation of sex were studied in several research projects. ${ }^{(37,42,43)}$ According to a Brazilian study, one of the reasons male adolescents are more likely to initiate sex is because they believed that sex is an uncontrollable instinct in males. ${ }^{(44)}$ In addition, males found it easier to engage in sexual intercourse without a sense of emotional commitment as compared to females. ${ }^{(45)}$

The in-depth interviews and essay writing exercise further revealed several additional key findings concerning sexual initiation among the adolescents in our study. One predominant theme was sex as a means of expressing love and strengthening a relationship, which supports studies that highlight the fact that individuals engage in sexual intercourse in order to express their affection toward their partner. ${ }^{(44,46-50)}$ Comparable to the motivational-instigation structure within the personality system of problem behaviour, adolescents who value affection are exposed to pressures that lead to the urge to engage in sexual intercourse. ${ }^{(1)}$

Another dominant theme voiced by the adolescents regarding their first sexual encounter was the 'partner factor', such as the insistence or influence of the partner. Similar findings have been noted by previous investigators. ${ }^{(50-52)}$ Some adolescents believed that fulfilling their partner's request for sex could maintain their relationship and avoid conflicts with their partner. They also believed that engagement in sexual intercourse would keep their partner interested in them. For some, it meant reciprocating all the good deeds their partner had done for them.

Another reason for having sex stated by many participants was their inability to control their sex drive. A similar finding was reported in one study in which adolescents reported intense sexual urges that were difficult to ignore. ${ }^{(53)}$ This urge may be influenced by other factors such as low religiosity, lack of parental monitoring, permissive attitudes of parents, and underestimation of their own risk for adverse consequences, all of which further complicate the problem. Another theme that emerged was issues within the family. Initiating sex to relieve stress has been pointed out by adolescent study subjects of another study. ${ }^{(47)}$ Having problems at home tends to encourage adolescents to seek stress relief outside the home. Adolescents who are bored will draw on sexual intercourse as a way to release the tension related to their families without realising the short- and long-term consequences of doing so. The aforementioned findings, however, are subject to biases, especially since the study was conducted among adolescents who mostly have experienced some form of issues, such as sexual abuse. Thus, similar results from adolescents in the general population may only be found for certain factors.

The following limitations should be noted when interpreting the findings of the present study. First, as only incarcerated adolescents from welfare institutions were recruited, the study population is not representative of adolescents in the general Malaysian population. However, given that the sample selection was drawn from more than half of all welfare institutions within the 11 states in peninsular Malaysia, the findings can thus be considered representative of incarcerated adolescents in the country. Second, as in-depth interviews were used to collect some sensitive personal information, there may have been social desirability bias. Nevertheless, this would have been partly corrected by the essay writing exercise. Third, as this is a cross-sectional study, causal relationships between factors and sexual initiation can only be determined by carefully studying the temporal relationships between these factors. Thus, the survey design makes it difficult to determine whether the exposure factor precedes the outcome factor. Finally, in the qualitative phase of the study, there were insufficient 
opportunities to analyse data during the data collection period. Therefore, the interviews could not be tailored to explore additional information on new themes that unexpectedly emerged during data collection. However, the use of essay questions as an additional tool helped to neutralise this problem.

The findings of this study are of public health significance. First, the identification of the specific factors that predispose incarcerated adolescents to early sexual initiation will make an important contribution to current efforts in the prevention and control of STIs, including HIV/AIDS, and other reproductive health problems. Specific interventions can be targeted at these adolescents to prevent poor outcomes such as teenage pregnancy and illnesses like HIV/AIDS. For example, this study offers a simple yet sensitive screening process for all incarcerated adolescents to ensure that they receive the appropriate management, advice and counselling regarding sexual and reproductive health upon admission to welfare institutions.

Second, government policies and allocation of funds to control unwanted pregnancies, unsafe abortions and pregnancy-related complications among this high-risk group still leave much to be desired. A review of adolescents' health policies within the Western Pacific Region revealed some policies concerning adolescent general health, but specific sexual and reproductive health policies for at-risk adolescents are still not addressed. Thus, additional policies targeting this group can be proposed based on the findings of the current study.

Third, many studies on adolescent sexual behaviour were either cross-sectional or solely qualitative, whereas this study adopted a sequential mixed-method approach. The combination of quantitative and qualitative approaches provided opportunities in terms of: (a) the resulting mixture, which yields complementary strengths and non-overlapping weaknesses; (b) expanding or complementing a set of results; and (c) discovering information that would otherwise have been missed if only one of the two approaches had been used. In recent years, there has been great emphasis on translational research, which aims to convert research findings into practical applications that meet people's needs. ${ }^{(54)}$ In order to disseminate the results of research for practical purposes, researchers must speak at least two languages - the technical language of research and a simplified language that communicates research messages adequately and in an easily understandable fashion. Thus, words become as important as numbers in writing up research. ${ }^{(55)}$ Mixed-method research has the advantage of allowing, as well as employing, both quantitative and qualitative approaches. ${ }^{(55)}$

Further studies may be warranted, as certain areas and variables were not covered in this study, which focused solely on incarcerated adolescents placed in public welfare institutions. There is thus a need to replicate this study using other populations, such as street adolescents, as well as those in private welfare institutions. Additionally, culture as a variable was not examined in the present study. As Malaysia is a multicultural community, a study using appropriate measures for culture could allow researchers to generalise their findings to diverse groups of Malaysians.

In conclusion, the results of this study suggest that the initiation of sexual intercourse among incarcerated adolescents is predominantly determined by individual factors, such as a history of sexual abuse during childhood, previous substance use, viewing of pornography, and the perception of sex as an expression of love. These factors are, however, modifiable and should be addressed through innovative programmes and policies, such as workshops on parenting skills that help caregivers understand the importance of nurturing their children and discuss various ways of getting help should child abuse or substance use be suspected. As it is also important for adolescents to communicate about their sexual and reproductive health issues, sexual and reproductive health programmes should be conducted in schools and welfare institutions. This will help adolescents discuss topics such as healthy relationships and sex, and the consequences of early initiation of sex can be covered more thoroughly.

\section{ACKNOWLEDGEMENTS}

This study was supported by the Postgraduate Research Fund, University of Malaya, Kuala Lumpur, Malaysia (grant number: PS166/2009B). The authors would like to acknowledge the Social Welfare Department of Malaysia, Ministry of Women, Family and Community Development for contributing to this study.

\section{REFERENCES}

1. Rew L. Adolescent Health: A Multidisciplinary Approach to Theory, Research, and Intervention. Thousand Oaks: Sage Publications, 2005.

2. United Nations Children's Fund (UNICEF). The State of the World's Children 2011. Adolescence: An Age of Opportunity. Available at: http://www. unicef.org/sowc2011/pdfs/SOWC-2011-Main-Report_EN_02092011.pdf. Accessed July 11, 2011.

3. World Health Organization Western Pacific Region. Health of Adolescents in Malaysia [online]. Available at: http://www.wpro.who.int/topics/ adolescent_health/malaysia_fs.pdf. Accessed March 12, 2011.

4. Da Ros CT, Schmitt Cda S. Global epidemiology of sexually transmitted diseases. Asian J Androl 2008; 10:110-4.

5. World Health Organisation. Health topics: HIV/AIDS [online]. Available at: http://www.who.int/topics/hiv_aids/en/. Accessed July 1, 2011.

6. Kaestle CE, Halpern CT, Miller WC, Ford CA. Young age at first sexual intercourse and sexually transmitted infections in adolescents and young adult. Am J Epidemiol 2005; 161:774-80.

7. Ma Q, Ono-Kihara M, Cong L, et al. Early initiation of sexual activity: a risk factor for sexually transmitted diseases, HIV infection, and unwanted pregnancy among university students in China. BMC Public Health 2009; 9:111.

8. Gowen LK, Aue N, eds. Sexual Health Disparities among Disenfranchised Youth [online]. Available at: http://www.pathwaysrtc.pdx.edu/pdf/ pbSexualHealthDisparities.pdf. Accessed July 1, 2011.

9. Hendershot CS, Magnan RE, Bryan AD. Associations of marijuana use and sex-related marijuana expectancies with HIV/STD risk behavior in high-risk adolescents. Psychol Addict Behav 2010; 24:404-14.

10. Houck CD, Lescano CM, Brown LK, et al. "Islands of Risk": subgroups of adolescents at risk for HIV. J Pediatr Psychol 2006; 31:619-29. 
11. Vermund SH, Alexander-Rodriguez T, Macleod S, Kelley KF. History of sexual abuse in incarcerated adolescents with gonorrhea or syphilis. J Adolesc Health Care 1990; 11:449-52.

12. Department of Social Welfare, Malaysia. Welfare Institutions [online]. Available at: http://www.jkm.gov.my/content.php?pagename=Kanakkanak\&lang=bm. Accessed December 31, 2010.

13. Dean AG, Sullivan KM, Soe MM. OpenEpi: Open Source Epidemiologic Statistics for Public Health, Version 2.3.1 [online]. Available at: www. OpenEpi.com. Accessed June 1, 2009.

14. Ministry of Health, Malaysia. The Third National Health and Morbidity Survey (NHMS III); Malaysia: Institute of Public Health, 2008.

15. Li X, Feigelman S, Stanton B. Perceived parental monitoring and health risk behaviors among urban low-income African-American children and adolescents. J Adolesc Health 2000; 27:43-8.

16. Small SA, Kerns D. Unwanted Sexual Activity Among Peers During Early and Middle Adolescence: Incidence and Risk Factors. J Marriage Fam 1993; 55:941-52.

17. Mohd Jamil BHY. Validity and Reliability Study of Rosenberg Self-Esteem Scale in Seremban School Children. Malays J Psychiatr 2006; 15:35-9.

18. Crandall R. The measurement of self-esteem and related constructs. In: Robinson JP, Shaver PR, eds. Measures of social psychological attitudes. Rev ed. Ann Arbor: Institute for Social Research, 1973.

19. Rosenberg M, ed. Society and the adolescent self-image. Princeton, NJ: Princeton University Press, 1965.

20. Wylie RC. The Self-Concept. Vol 1: A review of methodological considerations and measuring instruments. Rev ed. Lincoln, Nebraska: University of Nebraska Press, 1974.

21. Teenage Knowledge of Contraception and Sexual Health: Questionnaire Study in West Yorkshire 2002 [online]. Available at http://www.bradfordvts. co.uk/wpcontent/onlineresources/0002 mrcgp/noe/projecttypes/ questionnaire \%20-\%20teenage \%20knowledge \%20of\%20sexual\%20 health.pdf. Accessed June 25, 2009.

22. Kooiman CG, Ouwehand AW, ter Kuile MM. The Sexual and Physical Abuse Questionnaire (SPAQ). A screening instrument for adults to assess past and current experiences of abuse. Child Abuse Negl 2002; 26:939-53.

23. Black MM, Oberlander SE, Lewis T, et al. Sexual intercourse among adolescents maltreated before age 12: a prospective investigation. Pediatrics 2009; 124:941-9.

24. American Psychological Association. Understanding Child Sexual Abuse: Education, Prevention and Recovery [online]. Available at: http://www. apa.org/pubs/info/brochures/sex-abuse.aspx. Accessed January 1, 2012.

25. Polit DF, White CM, Morton TD. Child sexual abuse and premarital intercourse among high-risk adolescents. J Adolesc Health Care 1990; $11: 231-4$.

26. Meier AM. Adolescents' Transition to First Intercourse, Religiosity, and Attitudes about Sex. Soc Forces 2003; 81:1031-52.

27. Wong ML, Chan RK, Koh D, et al. Premarital sexual intercourse among adolescents in an Asian country: multilevel ecological factors. Pediatrics 2009; 124:e44-52.

28. Yan $\mathrm{H}$, Chen $\mathrm{W}, \mathrm{Wu} \mathrm{H}$, et al. Multiple sex partner behavior in female undergraduate students in China: a multi-campus survey. BMC Public Health 2009; 9:305.

29. Alexander M, Garda L, Kanade S, Jejeebhoy S, Ganatra B. Correlates of premarital relationships among unmarried youth in Pune District, Maharashtra, India. Int Fam Plan Perspect 2007; 33:150-9.

30. Brown JD, L'Engle KL, Pardun CJ, et al. Sexy media matter: exposure to sexual content in music, movies, television, and magazines predicts black and white adolescents' sexual behavior. Pediatrics 2006; 117:1018-27.

31. Collins RL, Elliott MN, Berry SH, et al. Watching sex on television predicts adolescent initiation of sexual behavior. Pediatrics 2004; 114:e280-9.

32. Wei R, Lo VH, Wu H. Internet Pornography and Teen Sexual Attitudes and Behavior. China Media Res 2010; 6:66-75.
33. Alemu H, Mariam DH, Belay KA, Davey G. Factors predisposing out-ofschool youths to HIV/AIDS-related risky sexual behaviour in northwest Ethiopia. J Health Popul Nutr 2007; 25:344-50.

34. Calafat A, Juan M, Becoña E, Mantecón A, Ramón A. [Risky sexual behaviour and drug use in recreational nightlife context. A gender perspective]. Psicothema 2009; 21:227-33. Spanish.

35. Frank S, Esterhuizen T, Jinabhai C, Sullivan K, Taylor M. Risky sexual behaviours of high-school pupils in an era of HIV and AIDS. S Afr Med J 2008; 98:394-8.

36. Khasakhala AA, Mturi AJ. Factors associated with risky sexual behaviour among outof-school youth in Kenya. J Biosoc Sci 2008; 40:641-53.

37. Lee LK, Chen PC, Lee KK, Kaur J. Premarital sexual intercourse among adolescents in Malaysia: a cross-sectional Malaysian school survey. Singapore Med J 2006; 47:476-81.

38. Morojele NK, Brook JS, Kachieng'a MA. Perceptions of sexual risk behaviours and substance abuse among adolescents in South Africa: a qualitative investigation. AIDS Care 2006; 18:215-9.

39. Rosengard C, Stein LA, Barnett NP, et al. Co-Occurring Sexual Risk and Substance Use Behaviors Among Incarcerated Adolescents. J Correct Health Care 2006; 12:279-87.

40. Hamilton M. What's Happening To Our Boys? Sydney: Penguin Group, 2010.

41. Upadhyay UD, Hindin MJ, Gultiano S. Before first sex: gender differences in emotional relationships and physical behaviors among adolescents in the Philippines. Int Fam Plan Perspect 2006; 32:110-9.

42. Blum RW, Beuhring T, Shew ML, et al. The effects of race/ethnicity, income, and family structure on adolescent risk behaviors. Am J Public Health 2000; 90:1879-84.

43. Santelli JS, Kaiser J, Hirsch L, et al. Initiation of sexual intercourse among middle school adolescents: the influence of psychosocial factors. J Adolesc Health 2004; 34:200-8.

44. Borges AL, Nakamura E. Social norms of sexual initiation among adolescents and gender relations. Rev Lat Am Enfermagem 2009; 17:94-100.

45. Carroll JL, Volk KD, Hyde JS. Differences between males and females in motives for engaging in sexual intercourse. Arch Sex Behav 1985; 14:131-9.

46. Patrick ME, Palen LA, Caldwell L, et al. A Qualitative Assessment of South African Adolescents' Motivations For and Against Substance Use and Sexual Behavior. J Res Adolesc 2010; 20:456-81.

47. Low WY, Ng CJ, Fadzil KS, Ang ES. Sexual issues: let's hear it from the Malaysian boys. J Mens Health Gend 2007; 4:283-91.

48. Ng CJ, Kamal SF. Bridging the gap between adolescent sexuality and HIV risk: the urban Malaysian perspective. Singapore Med J 2006; 47:482-90.

49. Marston C, King E. Factors that shape young people's sexual behaviour: a systematic review. Lancet 2006; 368:1581-6.

50. Kempadoo K, Dunn LL. Factors that Shape the Initiation of Early Sexual Activity Among Adolescent Boys and Girls: A Study in Three Communities in Jamaica. Jamaica: Centre for Gender and Development Studies, University of the West Indies, 2001.

51. Sujay R. Premarital Sexual Behaviour among Unmarried College Students of Gujarat, India. New Delhi: Population Council, 2009.

52. Skinner SR, Smith J, Fenwick J, Fyfe S, Hendriks J. Perceptions and experiences of first sexual intercourse in Australian adolescent females. J Adolesc Health 2008; 43:593-9.

53. Papathanasiou, I, Lahana E. Adolescence, Sexuality and Sexual Education. Health Sci J 2007; 29:1-8.

54. National Cancer Institute. Translational Research Working Group: TRWG Definition of Translational Research [online]. Available at: http:// www.cancer.gov/researchandfunding/trwg/TRWG-definition-and-TRcontinuum. Accessed February 22, 2012.

55. Brannen J. Mixed Methods Research: A discussion paper. United Kingdom: ESRC National Centre for Research Methods, 2005 